\begin{tabular}{|c|l|}
\hline Title & $\begin{array}{l}\text { The effect of repeated photographic identification and time delay on the accuracy of the final photographic } \\
\text { identification and the rating of memory }\end{array}$ \\
\hline Author(s) & Naka, Makiko; Itsukushima, Y ukio; Itoh, Y uji; Hara, Satoshi \\
\hline Citation & International Journal of Police Science and Management, 4(1), 53-61 \\
\hline Issue Date & 2002 \\
\hline Doc URL & http://hdl.handle.net/2115/44682 \\
\hline Type & article \\
\hline File Information & naka 079.pdf \\
\hline
\end{tabular}

Instructions for use 


\title{
The effect of repeated photographic identification and time delay on the accuracy of the final photographic identification and the rating of memory
}

\author{
Makiko Naka," Yukio Itsukushima, Yuji Itoh and Satoshi Hara \\ "Tokyo Metropolitan University, Faculty of Social Sciences and Humanities, \\ Department of Psychology, 1- 1 Minamiosawa. Hachioi-shi, Tokyo-to, Japan 192-0397; \\ Tel: +81-426-77-2101; Fax: +81-426-77-2100; E-mail: mnaka@bcomp.metro-u.ac.jp \\ Received: 8th February 2001
}

Makiko Naka, the editor of this issue, is a cognitive and developmental psychologist in Japan. She is an associate professor of Tokyo Metropolitan University. She has a broad interest in memory and language and has published papers in English and Japanese on eyewitness testimony, mother-child communication, and effect of writing on memory. Her main research interest now is eyewitness testimony and child interviews.

Itsukushima Yukio is a cognitive psychologist in Japan. He is a professor of Nihon University in Tokyo. He studies the impact of emotion on memory performance in the context of eyewitness identification.

Yuji Itoh is a cognitive psychologist in Japan. He is a professor at Keio University in Tokyo. He is interested in memory for faces, and studies the verbal overshadowing effect on face recognition. Satoshi Hara is a forensic psychologist in Japan. He is a professor at Surugadai University in Saitama. His research interest is the contentbased criteria analysis of testimony and confession.

\section{Abstract}

In the historically' well-knom case of Teigin Jiken (the ase of Imperial Bank), eyenimesses were presented with a large number of phoros repeatedly, during a six-momih imvestigation, before they finally identified a suspect. In this paper, by partially modelling their study on the imestigation after Teigin Jiken, the authors examine the possibly negative effect of repeated phow identification (RPI) and time delay on memory for a face, and subjects ratings of the state of memory and confidence. Lindergradrates participared in a staged evem followed by a dela)' with or withont RPI, and then the final photo identification. The results shoured a cumulative cffect of $R P I$ and time delay. In particular, subjects with RPI were less accurate in the final photo identification, and their vatings of the state of memory and confidence uere less calibrated to acourac).

\section{INTRODUCTION}

When a person witnesses a crime but cannot specify the suspect, the witness may be asked by law enforcement to go through a large set of photos to identify a suspect (nug shors). If the witness cannor identify the suspect, they may be presented with even more photos until they finally pick one out or give up. Although it is a common practice, one could raise the question whether being exposed to such a large number of photos would obscure the witness's memory for a face.

Teigin liken (the case of Imperial Bank), is an historically well-known criminal case



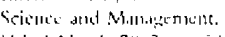

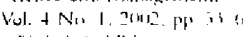
"reteinch Publivinug. $1+401-35:-5$ 
to the lapanese. On 26th January, 1948, a medical doctor visited $S$ Branch of Imperial Bank. The man announced that a customer of the branch was intected with dysentery and thus the clerks working there must take preventive medicine. In fact, it was poison and 12 clerks out of 16 were killed. Because this 'doctor' had visited two other branches beforehand, though failing to give medicine, nore than 40 people saw him. After six months of intensive search in vain, $\mathrm{SH}$ was arrested on rather weak evidence. Eyewitnesses went through photo identification and then a single line-up. Although many witnesses hesitated about identifying him in the beginning, they eventually did identify him as the perpetrator. $\mathrm{SH}$ pleaded not guilty, but he was sentenced to death in 1950. One of the main pieces of evidence was the identification by more than 40 witnesses. Though 50 years have passed, it is still argued it could have been misidentification (Morikawa, 1977).

In this case, the photo identification of $\mathrm{SH}$ took place six months after the event. In addition, witnesses were presented with many photos, up to 8,000 , in repeated photo identification conducted by police investigators and journalists. In the court of justice, 31 witnesses out of 40 studied by the authors mentioned the number of photos they saw during the investigation.
Ten witnesses said they saw tewer than ten photos, nine said ten to 100 photos, four said 100 to 1,000 photos, six said more than 1,000 photos, and two said 'nany'. Such practice could have obscured their memory, as one of them said 'I saw 30,000 to 40,000 photos at the police department. It's no good to see the photos in such an involuntary way. I had a dream watching at film in slow motion.

Being exposed to such a large number of photos as well as a long delay may indeed contaminate a witness's memory. 'There seems, however, to be no heed taken of this in investigations in those days and even today.' In this paper, by partially modelling the study on the Teigin Jiken investigation, the authors examined the possibly negative effect of time delay and repeated photo identification (RPI) on the performance of final photo identification, and subjects' ratings of the state of memory and confidence.

In the following, the authors first present a staged event (tea-tasting experiment), which was followed by some delay (30 minutes to five months) with or without RPI, and then the final photo identification. As is summarised in Table 1, five conditions were set up: A 30-minute delay without RPI (Condition 1); a three-week delay without RPI (Condition 2); a threeweek delay with RPI (Condition 3); a five-

Table 1: The description of conditions and the questionnaires used ${ }^{\dagger}$

\begin{tabular}{|c|c|c|c|c|c|}
\hline Condinon & Nimmber & $\begin{array}{l}\text { Repeated } \\
\text { idemificarion }\end{array}$ & Delar & $\begin{array}{l}\text { Fumal } \\
\text { idemification }\end{array}$ & $\begin{array}{l}\text { Target in the final } \\
\text { idestifarion }\end{array}$ \\
\hline Condition 1 & 37 & No & 30 minutes & Photo (1)) & Yes \\
\hline Condition 2 & 34 & No & 3 weeks & Photo (1)) & Yes \\
\hline Condition 3 & .33 & Yes $(C)$ & 3 weeks & I'horo (1)) & Yes \\
\hline Condition $t$ & 30 & No & 5 months & Photo (1)) & Yes \\
\hline Condition 5 & 34 & Yes (C) & 5 months & Photo (I)) & Yes: \\
\hline
\end{tabular}

1: Questionnaires used are shown in parentheses

(C) $=$ Questionnaire $C$ for the repeated photo identification.

(1) $=$ Questionnaire 1) for the final photo identification. 
month delay without RPI (Condition 4); and a five-month delay with RPI (Condition 5.)

\section{METHOD}

\section{Subjects}

One hundred and sixty-eight Japanese undergraduates from four universities in the Tokyo area participated in a dummy taste experiment and completed RPI and the final photo identification. Table 1 shows the number of subjects for each condition.

\section{Materials}

Four photo albums, each of which contained 100 different photos, were created. Photos were black-and-white photographs of Japanese males aged trom 25 to 60. The first three albums, which did not contain the target, were used for RPI. The fourth album, which contained the target, was used in the final photo identification. In addition, four kinds of questionnaires (Questionnaires A to D) were created.

\section{Procedures}

The experiment consisted of four parts:

(1) a dummy taste experiment wher the subjects met the target

(2) inmediate verbal description of the target's face

(3) the delay with or without three trials of photo identification

(t) the final photo identification.

The following are the details of each part. See Table 1 for the summary of conditions.

(1) A dummy laste experimont: The subjects participared in a dumny taste experiment in groups of 15 to 20 subjects. A male experimenter (target) in his mid-40s in a white robe announced that he wanted the subjects to taste two kinds of tea for evaluation. In order to draw the subjects' attention, he explained how to taste tea and asked the subjects to follow the instructions. (Just like I do, please retain the tea in your mouth for a while so you can taste it well.') After the subjects had tasted two kinds of tea, the experimenter left the room, and a female assistant came in and asked them to fill out Questionnaire A for evaluation of taste. During the taste experiment, the subjects could observe the experimenter for about five minutes from 2.0 to 2.5 metres away.

(2) Verbal description of the face: Approxinately 20 minutes after the taste experiment, all subjects were asked to answer Questionnaire B, in which they were to give a verbal description of the target's face. They also answered the same questionnaire before the final photo identification. The purpose of this questionnaire was to see how the verbal description might change over time, but the results are not reported in this paper. ${ }^{2}$

(3) Repeated photo identification: The subjects in conditions 3 and 5 were asked to attend three time trials of photo identification, once per week for three weeks. At each trial, subjects were individually given an album of 100 photos and Questionnaire C. By the end of these three trials, they had seen 300 different photos, which did not contain the target. The main questions asked in Questionnaire C were

(a) the state of memory before and after the photo identification [rated as 1: no memory, 2: vague, 3: clear]

(b) the possibility for identification [1: impossible, 2: uncertain, 3: possible]

(c) the number of likely photos (There nay or may not be the target in the album, but exanume carefully and choose up to three photos that arc likely to be the experimenter.)

(d) the most likely photo ('Choose the most likely one from three candidates and make a decision whether or not he is the experimenter.). 
(4) The final phon identification: The subjects attended the final photo identification 30 minutes after the taste experiment (condition 1), three weeks after the taste experiment (conditions 2 and 3), or five months after the taste experiment (conditions 4 and 5). The subjects were individually given an album containing 100 photos, which included the target, and Questionnaire D. The main questions in (Questionnaire D were

(e) the state of memory before and after the photo identification

(f) the possibility of identification

(g) the most likely photo ("There might or might not be the target in the album, but examine carefully and choose a photo that is most likely to be the experimenter:)

(h) confidence in the choice (1: not confident at all to 5: very confident).

\section{RESULTS}

The following are the results from RPI (Questionnaire $C$ ) and the final photo identification (Questionnaire D).

\section{The repeated photo identification (Questionnaire C)}

Table 2 (top) shows

(a) the state of memory before and after identification

Table 2: Experiment results

\begin{tabular}{|c|c|c|c|c|c|c|}
\hline & \multicolumn{2}{|c|}{ (a) Srate of memory } & \multirow[t]{2}{*}{ (b) Possibility } & \multirow{2}{*}{$\begin{array}{l}\text { (i) Likely } \\
\text { pintos } \\
\text { (tip to 3) }\end{array}$} & \multicolumn{2}{|c|}{ (d) Most likely photo } \\
\hline & Before & Afier & & & Choike $\%$ & Confirmation \%o \\
\hline \multicolumn{7}{|l|}{$\begin{array}{l}\text { Repeated photo } \\
\text { identification }\end{array}$} \\
\hline First trial & 20 & 2.1 & 2.2 & 26 & 85 & 50 \\
\hline Second trial & 1.9 & 2.11 & 1.9 & 2.2 & 85 & 21 \\
\hline \multirow[t]{3}{*}{ Third trial } & 1.9 & 1.8 & 1.8 & 2.2 & 83 & 16 \\
\hline & \multicolumn{2}{|c|}{ (e) State of memor) } & \multirow[t]{2}{*}{ (f) Possibiliry } & \multirow{2}{*}{\multicolumn{2}{|c|}{ (Q) Correct decisun \% }} & \multirow[t]{2}{*}{ (h) Confitente } \\
\hline & Before & Afrer & & & & \\
\hline \multicolumn{7}{|l|}{$\begin{array}{l}\text { Final photo } \\
\text { identification }\end{array}$} \\
\hline $\begin{array}{l}\text { Condition l } \\
\text { (No. 30 min.) }\end{array}$ & 2.1 & 2.5 & 2.3 & 78 & & 3.3 \\
\hline $\begin{array}{l}\text { Condition } 2 \\
\text { (No. } 3 \text { wk.) }\end{array}$ & 20 & 2.6 & 2.2 & $x+$ & & 3.1 \\
\hline $\begin{array}{l}\text { Condicion } 3 \\
\text { (Yes, } 3 \text { wk.) }\end{array}$ & 1.9 & 2.3 & 1.8 & 58 & & 3.1 \\
\hline $\begin{array}{l}\text { Condition } 4 \\
(\mathrm{No}, 5 \mathrm{mo} .)\end{array}$ & 1.8 & 2.2 & 1.8 & 58 & & 2.9 \\
\hline $\begin{array}{l}\text { Condition } 5 \\
\text { (Yes, } 5 \text { mo.) }\end{array}$ & 1.9 & 2.0 & 1.9 & 42 & & 2.8 \\
\hline
\end{tabular}


(b) the possibility for identification on a three-point scale

(c) the number of photos that are likely to be the target (up to three photos)

(d) the nost likely photo and the ratio of subjects who confirmed the photo as the target, even though the target was never present in these trials.

A 3 (repetition) × 2 (before/after) ANOVA conducted on (a) state of memory resulted in the main effect of repetition $[F(2,340)$ $=32.52, p<.01]$. The rating decreased over trials with the significant differences berween each trial $(2.1,1.9,1.8$ for the first, second and third trial respectively), suggesting that the subjects became less certain of their memory as they repeated the photo identification. As for (b) the possibility and (c) the number of the likely photos, oneway ANOVAs yielded the main effect of repetition $[F(2,204)=24.63, p<.01$; $F(2,214)=17.26, p<.01]$. The possibility as well as the number of photos decreased over trials, suggesting growing uncertainty in subjects $(2.3,2.0,1.9$ for the possibility, and $2.7,2.3,2.1$ for the number of photos for each trial respectively.) It should be noted, however, as shown in Table 2, that more than 80 per cent of subjects chose (d) a most likely photo and nuany confirmed it as the target.

\section{The final photo identification}

Table 2 (botton) shows

(e) the state of memory before and after identification

(f) the possibility for identification

(g) the ratio of subjects who chose the correct photo

(h) the confidence in their choice.

As for (e) the state of menory, a 5 (condition) $\times 2$ (correct/incorrect) $\times 3$ (before/ after) ANOVA yiclded the main effect of correct/incorrect and betore/after $[F$ (1,
$154)=28.83, p<.01 ; F(1,154)=40.24$, $p<.01]$. The subjects who chose the correct photo rated the state of memory higher than those who did not $(2.2 \mathrm{vs} 1.8)$, which indicates the positive relationship between the rating and the accuracy. Furthermore, the rating increased from pre-decision to post-decision (1.9 ws 2.2), suggesting that the subjects could gauge the state of memory better after they had made a decision. The interaction of condition $\mathrm{x}$ correct/ incorrect was significant $[F(4,154)=3.28$, $p<.05]$. As shown in Figure 1 , the difference between the rating by correct subjects and incorrect subjects was greater for conditions 1, 2 and 4 (without RPI) than for conditions 3 and 5 (wich RPI.) Finally, the interaction of correct/incorrect $x$ before/ after was significant $[F(1,154)=18.87$. $p<.01]$. As shown in Figure 2, there was no difference in the pre-decision rating between the correct and incorrect subjects, but the post-decision rating was significantly higher for the correct subjects than for the incorrect subjects, which suggests again that the post-decision rating reflects accuracy better.

A 5 (condition) $\times 2$ (correct/incorrect) AN IVA conducted on $(\mathrm{f})$ the possibility revealed the main effect of condition $[F(1$, $157)=3.84, p<.011$, with a contrast between conditions 2 and 3 , confirming that repeated identification affected the cognisance of their performance.

Figure 3 shows (g) the ratio of subjects who made the correct choice. 'The delay and RPI scem to have an accumulative effect on the accuracy of identification $\left[X^{2}\right.$ $=17.22, p<.01]$. The $X^{-2}$ score for the 2 (correct/incorrect) $\times 2$ (with RPI/without RPI) table (ie conditions 1.2 and $+1 s$ conditions 3 and 5 as shown in Figure 3 . centre) was significant $\left[X^{2}=10.29, p<.01\right]$, showing RPI reduced the correct chorce. Likewise, the $X^{2}$ score for the 2 (correct) incorrect) $\times 3$ (30 nunutes/three weeks/five months) table (ie condition 1 is conditions 
Figure 1

The state of memory for correct and incorrect subjects

Figure 2 The state of memory before and after the identification
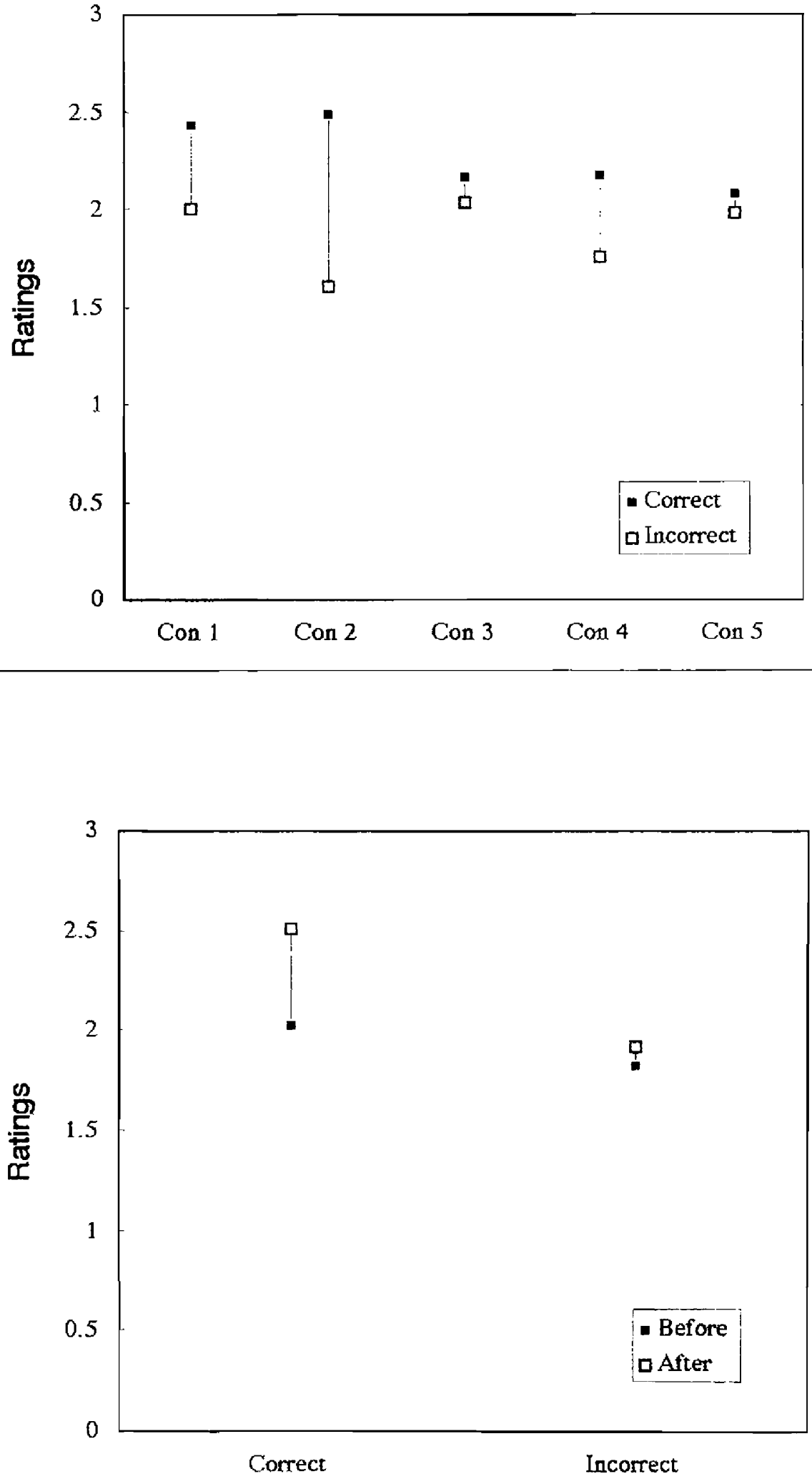


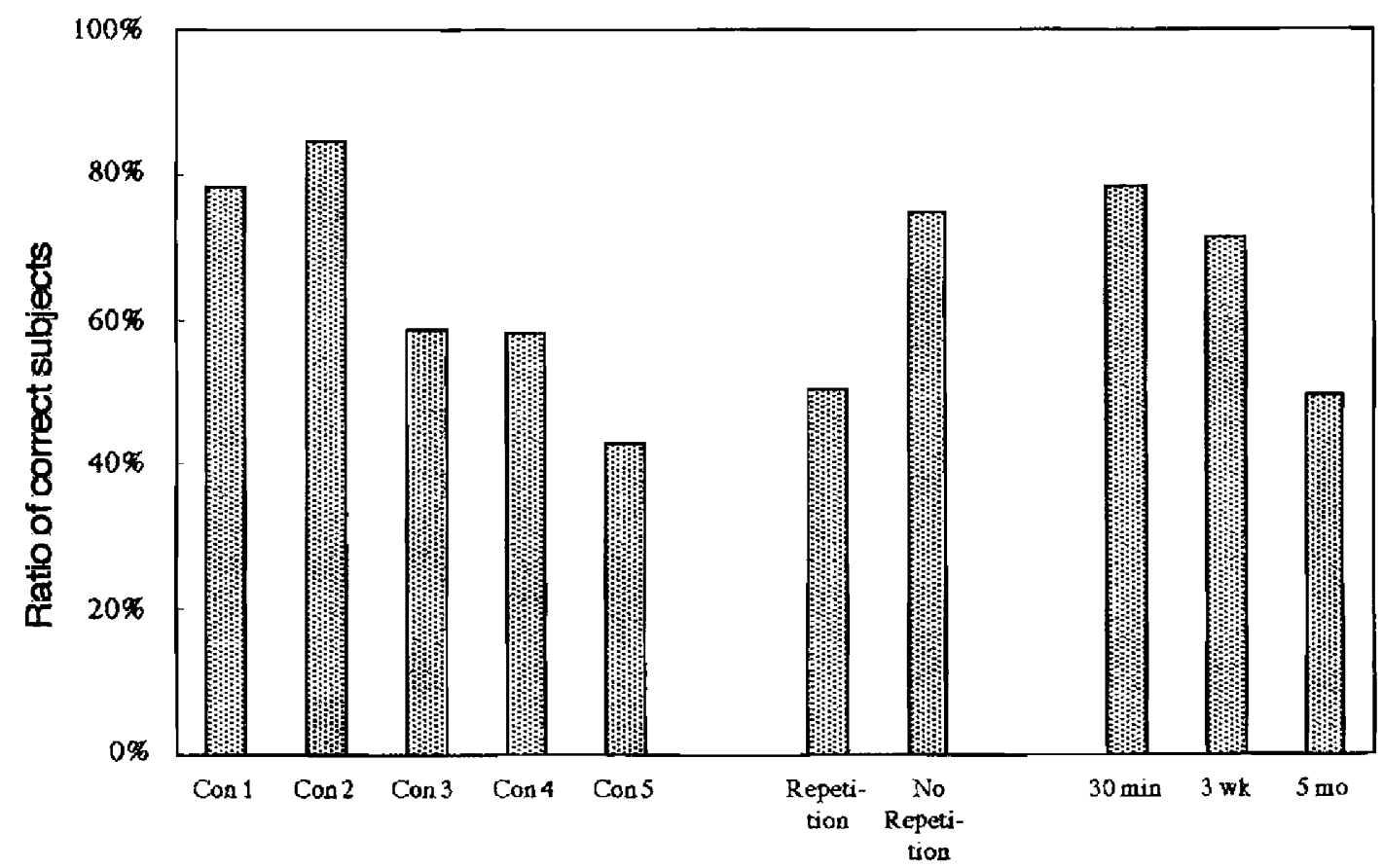

2 and 3 us conditions 4 and 5 , as shown in Figure 3 , right) was significant $\left[X^{-2}=10.52\right.$, $p<.01]$, confirnung the delay also decreases the accuracy.

Finally, a 5 (condition) $\times 2$ (correct/ incorrect) ANOVA applied to (h) the confidence yielded the main effect of correct/ incorrect $[F(1,1.31)=50.52, p<.01]$. The confidence was higher tor the subjects who chose the correct photo than for those who did not (3.9 $1: 2.1)$, which suggested the positive relationship between confidence and accuracy.

\section{DISCUSSION}

The present study examined the eftect of repeated photo identification (RPI) on the accuracy of the final photo identification. and on the sute of memory and confidence. The main findings are as follows.

First, RPI affects the state of memory and the prediction of one's pertormance (the possibility for identification). Subjects' ratings decreased over trials, suggesting they became less certain of their memory.

Secondly, RPI reduces the subjects' sensitivity to the sate of memory and confidence for the final photo identification. In conditions 1,2 and 4 (without RPI), those who chose the correct photo rated the state of memory higher than those who did not. On the other hand, in conditions 3 and 5 (with RPI), no difference was observed between the ratings of correct and incorrect subjects. Likewise, in conditions 1, 2 and $t$, the post-decision rating was higher than the pre-decision rating, while there was no such difference in conditions 3 and 5. Although some research warns that confidence cannot be used as an indicator of accuracy (Bothwell, Deffenbacher and Brigham, 1987; Juslin, Olsson and Winman, 1996; Wells and Turtle, 1987), there are substantial reports showing the positive correlation berween the accuracy and the confidence, especially the post-decision confidence (eg Brigham et al., 1982; Kratka and Penrod, 1985; Naka, Itsukushima and Itoh, 1996;
Figure 3

The ratio of correct subjects in the final photo identification 
Sporer, 1992). It is worth noting that the relationship between the accuracy and confidence may change depending on how the subjects spend the retention interval. Engaging in RPI could seriously deteriorate the correlation.

Finally, and most importantly, RPI decruases the accuracy of identification. The ratio of correct choice decreased by about 20 per cent due to repetition.

Many factors must be contributing to the negative effect of repeated photo identification. Menory decay due to delay should be one factor (Lee et al., 1998; Naka, Itsukushima and Itoh, 1996). Interference or suppression from recognising distracters may be another (Anderson, Bjork and Bjork, 1994; Anderson and Spellman, 1995). Commitment or carry-over effect might serve as well (Brigham and Cairns, 1988; Yu, Geiselman and Edward, 1993.) Furthermore, subjects might come to render more relative judgnent over the trials. During the three trials, many subjects chose the most likely photo' ( 85 per cent, 85 per cent and 82 per cent for each trial), and even confirmed it as the target ( 50 per cent, 22 per cent and 13 per cent for each trial.) If one confirms a person as a target, the logical consequence is that she/he cannot choose another one in the following trials. Nevertheless, 9 per cent of subjects confirmed different photos in two trials, ie confirmed two different photos as the target, and 3 per cent confirmed three different photos in three trials. Such behaviour suggests they chose a photo based on the relative sirnilarity rather than the absolute judgment (Beal, Schmitt and Dekle, 1995).

Further research is necessary to separate each factor and determine how each of them works. Yet in practice, it seems necessary to control the number of photos presented to eyewitnesses. The more one is presented with photos, the more likely one's momory as well as meta-menory is distorted.

\section{Notes}

1 The investigative procedure do not seem to be amended much even today. For example, in Jiminoto Hoka Jiken (the case of arson of LDP headquarters building), a witness who might or might not have seen a perpetrator was shown 374 photos four months after the event (Naka, Itsukushima and Itoh, 1996). The witness identified a person who became a suspect, though he was later acquitted.

2 Another reason for conducting Questionnaire $\mathrm{B}$ was to make the research more realistic because in most of cases, eyewitnesses are asked to give a verbal description of a perpetrator.

\section{REFERENCES}

Anderson, M. C., Bjork, R. A. and Bjork, E. L. (1994) 'Remembering can cause' forgetting: Retrieval dynamics in long-term memory', Joumal of Experinemal PSyelology: Learning, Menroy, and Cognition, Vol. 20, pp. $1063 \cdot 1087$.

Anderson, M. C. and Spellman, B. A. (1995) 'On the starus of inhibitory mechanisms in cognition: Memory retrieval as a model case', Psychologial Rovien, Vol. 102, pp. 68-100.

Beal, C. R., Schmitt, K. L. and Dekle, D. J. (1995) Eyewitness identification of children: Effects of absolute judgments, nonverbal response options, and event encoding, Lam and Human Behatior, Vol. 19, pp. $197-216$.

Bothwell, R. K., Deffenbacher, K. A. and Brigham, J. C. (1987) ' Correlation of eyewitness accuracy and confidence: Optimality hypothesis revisited', Jourmal of Applicd Psychology; Vol. 72, pp. 691-695.

Brigham, J. C. and Cairns, D. L. (1988) 'The effect of mugshot inspections on eyewitness identification accuracy, Jommal of Applied Social Psychology, Vol. 18, pp. 1394-1+10.

Brigham, J. C.., Maass, A., Snyder, L. D. and Spaulding, K. (1982) 'Accuracy of eyewitness identifications in a field setting', Jomrnal of Persomality and Social Psychology, Vol. 42, pp. 673.681. 
Juslin, P., Olsson, N. and Winman, A. (1996) Calibration and diagnosticity of confidence in eyewitness identification: Comments on what can be inferred from the low confidence-accuracy correlation, Joumal of Experimental Psychology: Learning, Memory, and Cognition, Vol. 22, pp. 1304-1316.

Krafka, C. and Penrod, S. (1985)

'Reinstatement of context in a field experiment on everwitness identification. Jourmal of Persomality and Social Psychology, Vol. 49, pp. 58-69.

Lee, E., Whalen, T., Jollymore, G., Read, C. and Swaffer, M. (1998) "The effects of delay on the performance of computerized feature systems for identifying', Betharion and Information Tedhrology, Vol. 17, pp. $29+300$
Morikawa, T. (1977) Gokuchu ichiman nichi $[10,000$ days in jail]', in lapanese,

Toshoshuppansha. Tokyo.

Naka, M., Itsukushima, Y. and Itoh, Y. (1996) 'Eyewitness testimony after three months: A ficld study' on memory for an incident in everyday life", Japanese Psycholoxical Research, Vol. 37, pp. 14- 23

Sporer, S. (1992) 'Post-dicting evewitness accuracy: Confidence, decision-times and person descriptions of choosers and nonchoosers', Europcan Journal of Social Psychology, Vol. 22, pp. 157. 180.

Wells, G. L. and Turtle, J. W. (1987) 'Eyewitness testimony research: Current knowledge and emergent controversies', Canadian Joumal of Behavional Science, Vol. 19 , pp. 363- 387. 